\title{
Ventriculoperitoneal shunt disconnection associated with loss of consciousness in a child patient: a case report and review of intra-abdominal complications of vp shunts
}

\begin{abstract}
Background \& Aim: The use of a ventriculoperitoneal (VP) shunt is the conventional method for the treatment of hydrocephalus. VP shunt failure is common. One of the complications of the VP shunt operation is the disconnection and migration of the shunt tube with predisposition to some complications like bowel perforation.

Case report: An 8-year-old boy with a right VP shunt was referred to our center because of progressive loss of consciousness in the morning. A CT scan of the head established moderate hydrocephalus. A shunt series presented a disconnection of the distal tube of the shunt as the distal part was free in the abdominal cavity. The patient experienced a complete shunt revision. The abdominal incision was revived and the tube removed from the abdominal cavity gently. The patient was discharged $72 \mathrm{~h}$ later.

Conclusion: Leaving disconnected catheters in situ brings the risk of possible future complications; so, early open or laparoscopic retrieval to eradicate disconnected shunt catheters must be considered.
\end{abstract}

Keywords: hydrocephalus, ventriculoperitoneal, shunt, disconnection
Volume 7 Issue 3 - 2017

Kaveh Haddadi, Hamid Reza Ganjeh Qazvini, Mohammad sahebi

Department of neurosurgery, Mazandaran University of Medical Science, and Sari, Iran

Correspondence: Kaveh Haddadi, Associated of professor, department of neurosurgery, spine fellowship scholar of Boston University Medical Center, orthopedic Research Center, Mazandaran University of Medical Science, and Sari, Iran, Email kh568hd@yahoo.com

Received: April 19, 2017| Published: August 04, 2017

\begin{abstract}
Abbreviations: CSF, cerebrospinal fluid; ventriculoperitoneal shunt

\section{Introduction}

Hydrocephalus is a deficiency in the production, movement, or absorption of cerebrospinal fluid (CSF) that leads to an irregular rise

years earlier, the child had experienced a VP shunt insertion, because of congenital hydrocephaly in infancy. In examination, his galasco coma scale (GCS) was 10. Andhe hasn't macrocephaly but has sunset eyes in inspection. His shunt pump worked normally on palpation. His body temperature was $37.7 \mathrm{C}$. He had some degree of guarding in an abdominal examination. There was no cervical stiffness. After stabilization, the patient had a complete work up.
\end{abstract} in CSF volume and, typically, pressure inside the brain. ${ }^{1}$ The first ventriculoperitoneal (VP) shunt was complete by Kausch in 1908. In spite of all the developments in neuroendoscopic surgery, the most public treatment for hydrocephalus remains the VP shunt. In children, a large quantity of tubing can be positioned intraperitoneal, diminishing the need for elective lengthening with growth, the operation is harmless, informal in nature, and is not a lengthy procedure. However, abdominal problems may happen, producing shunt dysfunction and acute hydrocephalus. ${ }^{2}$

The common complications associated with VP shunt operations are infection of the shunt, migration of the shunt tube, blockages and disconnections. Bowel perforation, inguinal hernia and hydrocele, cerebrospinal fluid pseudocyst and the extrusion of the distal end of the VP shunt through the anal opening can also occur.

However, due to the fact that the unplanned disconnection of the distal shunt tube is uncommon, we report a case of a distal tube interruption from the proximal shunt connector, leading to a shunt malfunction. The diagnosis became obvious preoperatively, and following a shunt revision, the patient made a full recovery.

\section{Case report}

An8-year-old boy with a right ventriculoperitoneal shunt was referred to our center by his parents because of progressive loss of consciousness in the morning. Prior to this, he had a7-day history of headache, vomiting and non-specific abdominal uneasiness. Eight

\section{Investigations}

A CT scan of the head established a moderate degree of hydrocephalus by a satisfactorily situated right ventricular catheter (Figure 1). A shunt series presented a disconnection of the distal tube of the shunt (Figure 2). The distal part was free in the abdominal cavity, especially in the direction of the right inguinal canal. The shunt tube was not presented in the cervical $\mathrm{x}$-ray. It appeared that the disconnection had occurred in the distal part of the shunt pump system in the neck. An abdominal and pelvic sonography did not show any evidence of mass or fluid collection or signs of infection. After urgent aspiration of the proximal valve the patient awoke quickly. Blood and CSF culture and analysis were negative for infections.

\section{Treatment}

The patient experienced a shunt revision. The abdominal incision was revived, and the distal catheter was found and removed gently from the abdominal cavity (Figures $3 \& 4$ ). The original shunt system consisted of a Medtronic Delta Neonate Valve that was substituted by a completely new Medtronic Delta Unitised Shunt due to the patient's age. Then, in a sterile fashion, the surgery was finished.

\section{Outcome and Follow-Up}

The patient had a fast and uncomplicated recovery, and was discharged $72 \mathrm{~h}$ later. A CT scan of the head 8 hours after surgery 
indicated definitely that the ventricular catheter was located satisfactorily and the hydrocephalus had been resolved (Figure 5).

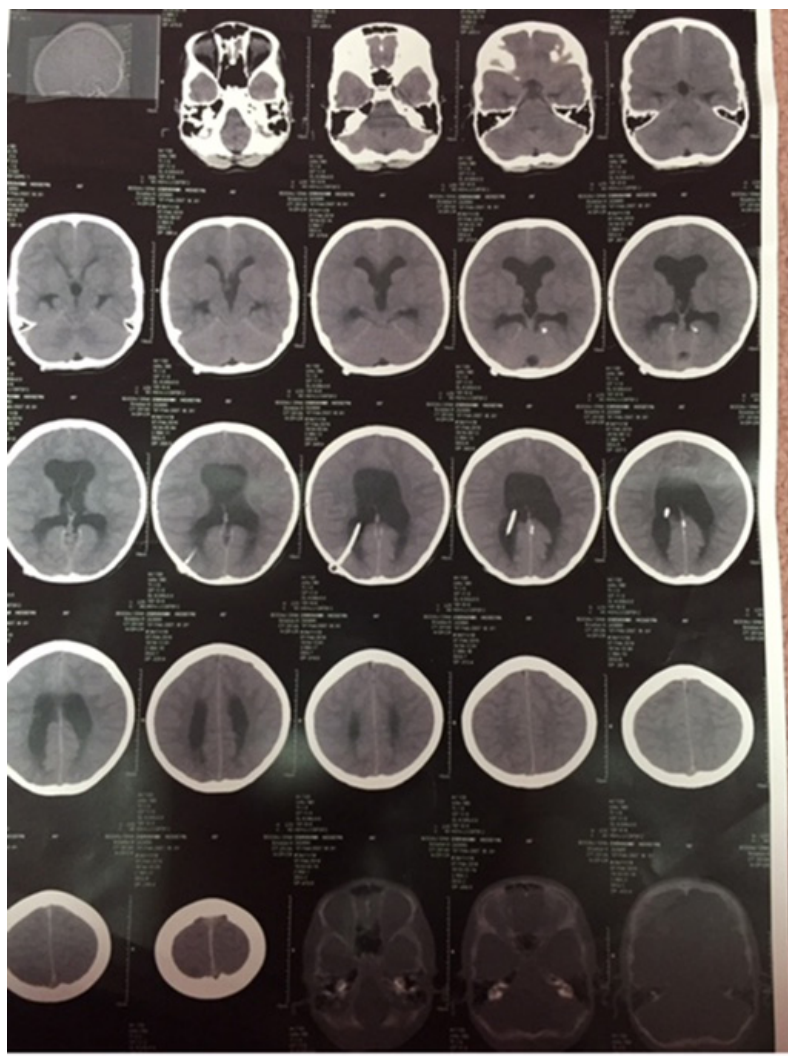

Figure I CT scan of the head showed moderate hydrocephalus due to a satisfactorily situated right ventricular catheter.

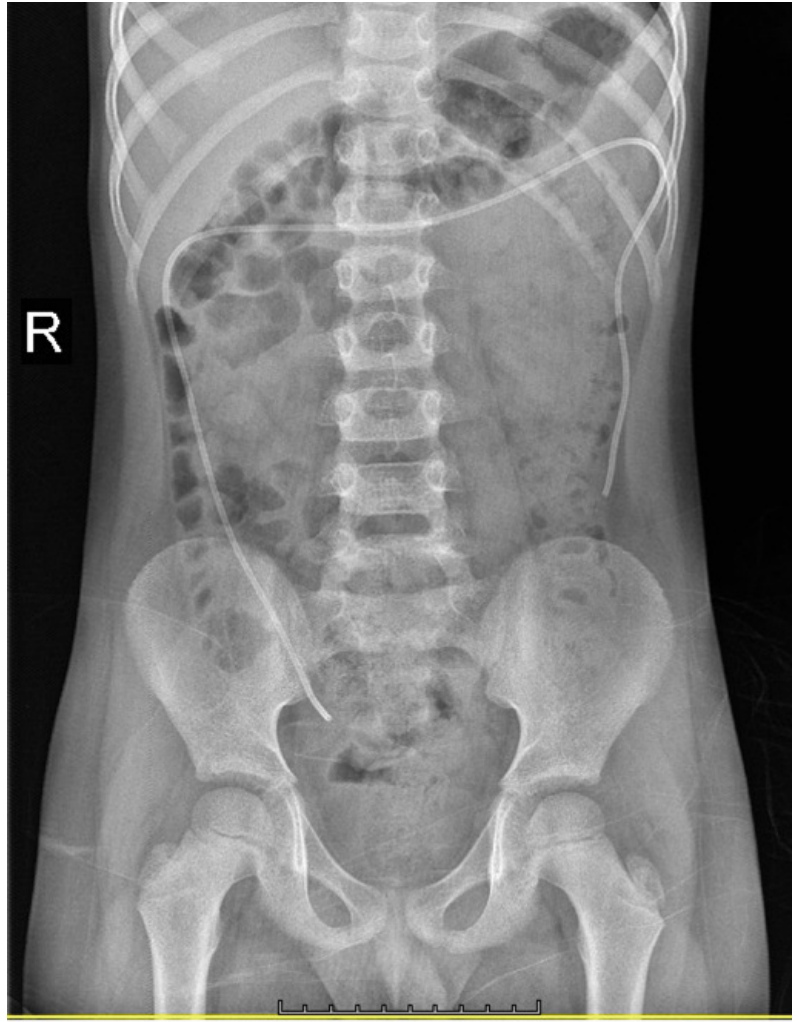

Figure 2 Shunt series presenting a disconnection of the distal tube of shunt.

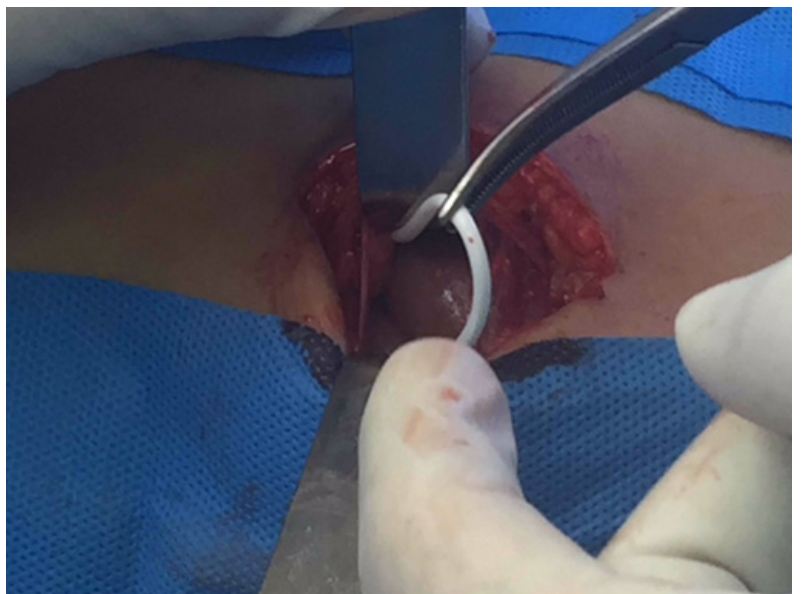

Figure 3 The distal catheter was found and removed from the abdominal cavity.

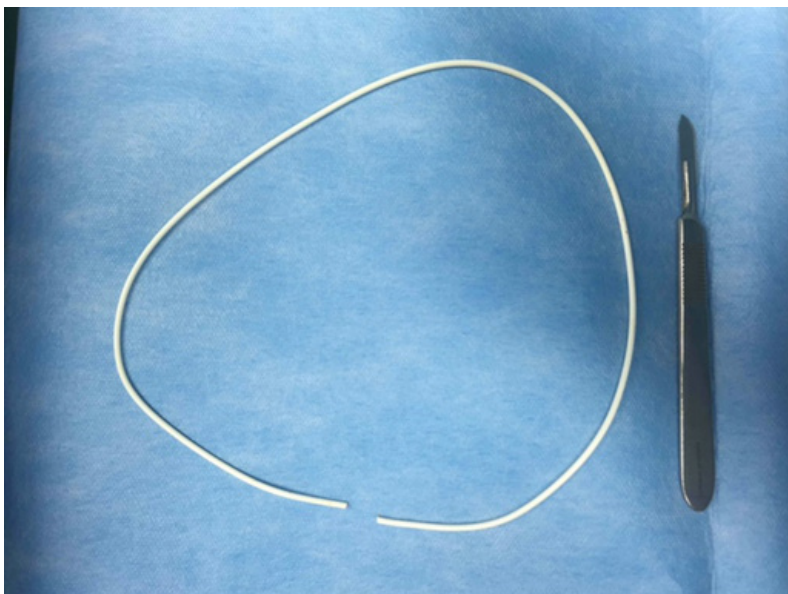

Figure 4 The distal catheter of the shunt system after removal from the abdominal cavity.

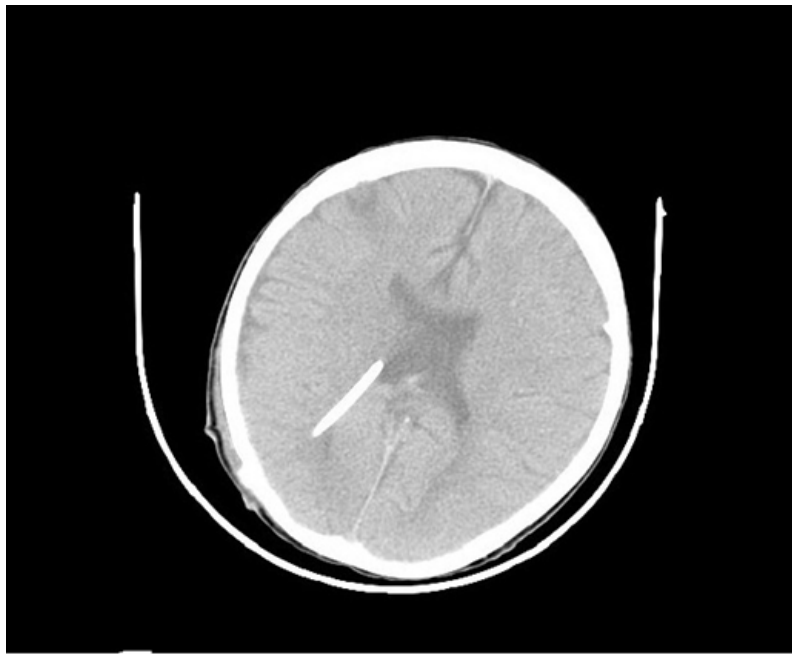

Figure $\mathbf{5}$ CT scan of the head 8 hours after surgery indicating definitely that the hydrocephalus had been resolved.

\section{Discussion}

The common complications of VP shunt surgery are infection of the shunt, blockage and disconnection, migration of the shunt tube,

Citation: Haddadi K, Qazvini HRG, Sahebi M.Ventriculoperitoneal shunt disconnection associated with loss of consciousness in a child patient: a case report and review of intra-abdominal complications of vp shunts. J Neurol Stroke. 2017;7(3): I-6. DOI: I0.15406/jnsk.2017.07.00237 
shunt failure, bowel perforation, cerebrospinal fluid (CSF) pseudocyst, inguinal hernia and hydrocele.

The incidence of abdominal complication reported in the writings is $10-30 \% .{ }^{3}$ Such complications might happen years after the initial insertion. These reports involve intestinal volvulus, pseudocyst, and catheter extrusion through the scrotum, umbilicus, vagina, or gastrointestinal tract. ${ }^{4}$ The distal component among the valve and the peritoneal catheter is the most probable site of disconnection. ${ }^{5}$ Cervical motion and growth might characterize the chief factors leading to shunt system discontinuity. ${ }^{6}$ It has been emphasized that usage of the leotard shunt system may offer the most promising method of avoiding shunt disconnection and its potential complications. ${ }^{5}$

Once a shunt system discontinuity is supposed, a radioisotopic shuntogram, temporary ligation, or intraoperative investigation must be started to evaluate the shunt function. Shunt catheters that migrate peritoneally bring the possibility of visceral injury, predominantly perforation of the bowel. These disconnected or fractured shunts can be revised by substituting or reconnecting the components, or by replacing the whole shunt system. In the modern era, the laparoscopic retrieval of migrated shunt catheters can be done safely, either as an emergency or an elective process. ${ }^{7}$ Perforation of the bowel by VP shunts is rare, and the incidence is only $0.1-0.7 \%$ of shunt surgery. ${ }^{8}$

The possible factors leading to this problem are tiny bowel walls on the part of children, sharp and stiff ends of the VP shunt, the use of a trocar by surgeons, lasting irritation by the shunt, prior surgery, infection and silicone allergy. ${ }^{9}$ In our case, the distal end of the shunt tubing was floating within the abdominal cavity and because the patient is asymptomatic an extensive intra-abdominal operation was not required. However, to avoid the above-mentioned complications, we preferred to remove the shunt tubing from the abdomen.

Although, laparoscopic retrieval or minimally invasive techniques to remove the disconnected shunt catheters could have been considered. ${ }^{4,10}$ our decision was to use complete shunt revision through open surgery. It was thought better that the length of the shunt catheter lying within the peritoneal cavity should not reach the inguinal area, even though it was in place over the dome of the liver.

Maybe during the time the distal disconnected tube leading to intestinal perforation or migration into the rectum or scrotum or other visceral organs. Perhaps we might replace the shunt surgery by endoscopic procedures in future to reduce this rare complication. In Conclusion, Migration of a disconnected shunt catheter into the abdominal cavity and subsequent bowel perforation is a rare but preventable complication.

\section{Conclusion}

Leaving disconnected catheters in situ brings the risk of possible future complications; so, early open or laparoscopic retrieval to eradicate disconnected shunt catheters must be considered.

\section{Learning points}

1. Migration of a disconnected shunt catheter into the abdominal cavity and subsequent bowel perforation is a rare but preventable complication.

2. Leaving disconnected catheters in situ brings the risk of possible future complications like Perforation of the bowel.

3. early open or laparoscopic retrieval to eradicate disconnected shunt catheters must be considered.

\section{Disclosures}

\section{Acknowledgements}

The authors thank the patient who participated in this study.

\section{Consent}

Written informed consent was obtained from the parents of the patient for publication of this case report and accompanying images.

\section{Ethical approval}

N/A.

\section{Sources of funding}

No funding required.

\section{Author contribution}

Kaveh Haddadi: literature search, writing the paper.

Hamid Reza Ganjeh Qazvini, mohammad sahebi: writing the paper.

\section{Conflicts of interest}

No conflict of interest.

\section{References}

1. Greenberg MS. Hydrocephalus. In Greenberg MS (Ed.), Handbook of Neurosurgery. Thieme Medical Publisher. New York, USA. 2006. p.180-207.

2. Nfonsam V, Chand B, Rosenblatt S, et al. Laparoscopic management of distal ventriculoperitoneal shunts complications. Surgical Endoscopy. 2008;22(8):1866-1870.

3. Bryant MS, Bremer AM, Tepas JJ 3rd, et al. Abdominal complications of ventriculoperitoneal shunts. Case reports and review of literature. $\mathrm{Am}$ Surg. 1998;54(1):50-55.

4. Huang HM, Lee WY, Chen DC. Disconnected subduroperitoneal shunt catheter induces silent bowel perforation: An unusual complication. Int J Surg Case Rep. 2011;2(5):76-78.

5. Ghritlaharey RK, Budhwani KS, Shrivastava DK, et al. Transanal protrusion of ventriculo-peritoneal shunt catheter with silent bowel perforation: report of ten cases in children. Pediatr Surg Int. 2007;23(6):575-580

6. Sathyanarayana S, Wylen EL, Baskaya MK, et al. Spontaneous bowel perforation after ventriculoperitoneal shunt surgery: case report and a review of 45 cases. Surg Neurol. 2000; 54(5):388-396.

7. Vinchon M, Baroncini M, Laurent T, et al. Bowel perforation caused by peritoneal shunts catheters: diagnosis and treatment. Neurosurgery. 2006;58(1):76-82

8. Park CK, Wang KC, Seo JK, et al. Transoral protrusion of a peritoneal catheter: a case report and literature review. Childs Nerv Syst. 2000;16(3):184-189.

9. Nebi Y, Nejmi K, Cahide Y, et al. Anal protrusion of ventriculo-peritoneal shunt catheter: report of two infants. J Pediatr Neurol. 2004;2:241-244.

10. Popa F, Grigorean VT, Onose G, et al. Laparoscopic treatment of abdominal complications following ventriculoperitoneal shunt. $J$ Med Life. 2009;2(4):426-436. 